\title{
Joyce para crianças brasileiras
}

Dirce Waltrick do Amarante

A ficção do escritor irlandês James Joyce chega às crianças brasileiras por meio da tradução de seu único conto infantil, "O Gato e o Diabo", feita por Antonio Houaiss, que assina a primeira versão brasileira de Ulisses (1922), e da ousada adaptação infantil de Finnegans Wake (1939), seu último e volumoso romance. Finnício Riovém (Lamparina, 2004), como se intitula a versão infanto-juvenil de Wake, é assinada por Donaldo Schüler, o tradutor do romance de Joyce para o português (ressalto que a palavra "tradução" é problemática, neste caso, já que o texto original utiliza mais de sessenta línguas como matéria-prima).

Quanto ao conto "O Gato e o Diabo", Joyce o escreveu para uma criança especificamente, o seu neto Stephen Joyce, que considerava o avô um grande contador de histórias infantis. Seu conto foi, no entanto, a única história que Joyce deixou registrada por escrito. Ela foi enviada por carta ao seu neto, em 1936, enquanto as outras foram relatadas apenas oralmente.

Pode-se dizer, numa primeira abordagem, que "O Gato e o Diabo" e suas narrativas para o público adulto têm muito em comum. Nesse conto, Joyce lança mão da mescla de línguas (o narrador da história fala inglês; já o diabo fala francês, com sotaque dublinense), de palavras inventadas e de alusões históricas e biográficas, além de retomar a questão irlandesa por meio, por exemplo, da figura ingênua do diabo. 
No universo cultural brasileiro, que me interessa considerar aqui, Finnício Riovém e "O Gato e o Diabo" trazem à discussão o papel da adaptação e de sua estreita relação com a tradução no contexto da literatura infanto-juvenil.

Quanto a Finnegans Wake, muito embora parte das inovações lingüísticas e dos recursos literários utilizados por Joyce para compor o romance seja na verdade criação original do escritor inglês Lewis Carroll (1832 - 1898), autor de livros dedicados ao público infantil, como Alice no País das Maravilhas (1865) e Através do Espelho (1871), certamente nenhuma criança se sentiria tentada a ler espontaneamente um romance com mais de seiscentas páginas, escrito num estilo e numa linguagem intrincada, que afasta até mesmo os leitores mais preparados e interessados em experimentos lingüísticos dessa natureza. Portanto, Finnegans Wake ficaria longe do público brasileiro jovem, se não fosse a sua "tradução adaptada", termo usado por Ferreira Gullar para se referir à sua adaptação de Dom Quixote, a qual, como afirma o poeta, "não pretende obviamente dispensar a leitura do texto original e, sim, pelo contrário, induzir o leitor a buscálo mais tarde, com tempo e disposição, para usufruir-lhe toda a riqueza de idéias (...)"1

Mas se a obra de Lewis Carroll, por seus jogos de linguagem, dentre outras características, tem sido considerada "intraduzível" por alguns estudiosos, o que dizer da obra de Joyce, construída, como já afirmei, sobre uma multiplicidade de idiomas?

É em Finnegans Wake que, segundo Jacques Derrida, notamos "um dos limites das teorias da tradução: eles tratam bem freqüentemente das passagens de uma língua para a outra e não consideram suficientemente a possibilidade para as línguas, a mais de duas, de estarem implicadas em um texto" ${ }^{2}$. O que Derrida questiona é "como traduzir um texto escrito em diversas línguas ao mesmo tempo?

CERVANTES, Miguel de. Dom Quixote de la Mancha. Tradução e adaptação: Ferreira Gullar. Rio de Janeiro: Revan, 2002, p. 09.

2 DERRIDA, Jacques. Torres de Babel. Belo Horizonte: UFMG, 2002, p. 20. 
Como 'devolver' o efeito de pluralidade? E se se traduz para diversas línguas ao mesmo tempo, chamar-se-á isso tradução?"3. Ainda de acordo com o mesmo filósofo, "o que a multiplicidade de idiomas vai limitar não é apenas uma tradução 'verdadeira', uma entr'expressão [entr'expression] transparente e adequada, mas também uma ordem estrutural, uma coerência do constructum (...). Seria fácil e até certo ponto justificado ver-se aí a tradução de um sistema em desconstrução". ${ }^{4}$

Desse modo, poder-se-ia dizer que a tradução de Finnegans Wake "está sujeita à lei de uma tradução necessária e impossível", uma tradução que se impõe e se nega infinitamente, como opina Umberto Eco a respeito de Wake.

Talvez fosse correto afirmar, então, que traduzir e adaptar são termos semelhantes quando se trata de verter para outros idiomas as obras de Carroll e Joyce, por exemplo, já que ambos os termos poderiam significar a simplificação de algum aspecto do original, visando contornar os problemas de linguagem, como já afirmou Sebastião Uchoa Leite ao se referir à tradução de Carroll, autor que ele próprio traduziu, ou tentou traduzir, para o português.

No caso de Finnício Riovém, entretanto, o enredo do romance de Joyce necessariamente precisaria se tornar acessível ao públicoalvo, no caso, o infantil. Assim, o termo adaptação seria sinônimo tanto de "condensação" quanto de tradução, ao visar tornar "legível" o texto original a partir da "recriação", expressão cara a Haroldo de Campos, de situações e trocadilhos para determinada faixa etária.

Na versão infantil de Finnegans Wake, ambientada mais no Rio de Janeiro do que em Dublin (cidade onde transcorre o romance de Joyce), as 628 páginas da narrativa original estão concentradas em 127, divididas em 21 capítulos, todos acrescidos de títulos. Sabe-se

\footnotetext{
Idem, ibidem.

Idem, p. 12.

Idem, p. 25.
} 
que Finnegans Wake se estende por 17 capítulos, os quais sempre foram publicados sem título ou identificação numérica.

Finnício Riovém recupera, no entanto, alguns dos mais importantes truques verbais de Carroll, reaproveitados por Joyce, como, por exemplo, as palavras-valise (duas palavras empacotadas numa só, segundo o hermeneuta Humpty Dumpty, personagem de Através do Espelho) e os trocadilhos. Além disso, Donaldo Schüler mantém de certo modo, no seu livro, a mescla de línguas existentes no romance de Joyce. Em Finnício Riovém, duas línguas, a portuguesa e a espanhola, são as mais evidentes, mas encontramos também o inglês, o francês, o italiano, etc. Donaldo igualmente recria alguns dos mais famosos soudsenses (palavras formadas pela associação de inúmeras letras, cujo sentido é melhor apreendido numa leitura em voz alta) de Finnegans Wake, como, por exemplo, o som do trovão, que dá início à narrativa joyceana.

Em Finnício Riovém, o tradutor de Joyce também reutiliza fragmentos narrativos de sua tradução de Finnegans Wake. Encontramos, assim, passagens comuns às duas "recriações" de Schüler, além do reaproveitamento de um recurso muito utilizado por ele na sua tradução para adultos: as palavras-cabide (como foram batizadas por mim e por Sérgio Medeiros, numa resenha sobre a tradução de Finnegans Wake), as quais, ao contrário das palavras-valise, são aquelas em que dois termos podem ser retirados de dentro de uma só palavra. Por exemplo: sol-e-nidade, macha dadas, Ex-gito, etc.

Embora concebido para crianças, Finnício Riovém conserva algumas passagens obscuras do romance de Joyce, além de citações e alusões históricas, literárias, filosóficas e mitológicas. O livro de Schüler recupera, aliás, os mitos mais evidentes de Finnegans Wake.

As fábulas tradicionais, recontadas por Joyce em todo o seu romance, também são recontadas na versão brasileira para crianças. Em Finnegans Wake, todavia, o escritor irlandês subtrai a moral do texto. No seu romance, convém lembrar, a moral só existe na medida em que seu conceito possa ser discutido. Uma herança talvez da literatura nonsense de Carroll. 
Segundo Elsie Leach, estudiosa de Carroll, quando o autor das Alices escreveu sua obra "os livros em inglês deveriam ser realistas, a fim de dar instruções essenciais de religião e/ou moralidade, para que a criança pudesse se tornar um adulto virtuoso e justo" ${ }^{\prime}$. Carroll, todavia, questionou em suas narrativas o conceito de moral. Lembro que o lema da Duquesa de Alice no País das Maravilhas era o seguinte: "Tudo tem uma moral, se pelo menos você a encontrar".

De fato, ao escrever a sua ficção, Carroll põe em xeque o conceito de moral. Joyce também o fez em Finnegans Wake, sua versão adulta da literatura nonsense vitoriana. Donaldo, contudo, recupera e inclui o conteúdo moralista em quase todos os capítulos de Finnício Riovém, na forma de um preceito moral, como se lia nas fábulas de Esopo, por exemplo. De certo modo, ele remete seu Joyce ao passado clássico e o faz dialogar com os fabulistas gregos.

Quanto ao aspecto moral nos livros para crianças, Walter Benjamin afirmou que "o livro infantil em suas primeiras décadas é edificante e moralista, e constitui uma simples variante deísta do catecismo e da exegese" ${ }^{\prime 7}$. Diria que, ainda hoje, a literatura infantil mantém esse caráter edificante, poucos escritores conseguiram escapar dessa fórmula e contrariar a crítica de Benjamin, segundo a qual se pode "duvidar que os jovens leitores" apreciem textos unicamente "por sua moral". No tocante às fábulas, por exemplo, é difícil acreditar que as crianças a utilizem como uma fórmula de edificação "de sua inteligência, como uma certa sabedoria que tudo ignora sobre a infância". Nas fábulas, Benjamin afirma que "as crianças se divertem muito mais com os animais que falam e agem como homens do que com os textos ricos em idéias". ${ }^{8}$ E, nem por isso, elas deixam de construir seu próprio universo.

\footnotetext{
PHILLIPS, Robert (org.). Aspects of Alice. Harmondsworth: Penguin Books, 1971, p. 122 BENJAMIN, Walter. Magia e técnica, arte e política: ensaios sobre literatura e história da cultura. São Paulo: Brasiliense, 1994, p. 236.

Idem, p. 238.
} 
Sobre a versão infantil de Finnegans Wake, caberia ainda dizer que, entre o romance de Joyce e o texto de Donaldo Schüler, muitas são as semelhanças e também as diferenças. Mas como esclarece Xem, personagem da versão de Donaldo: “-Eu não disse que quero modelo para fazer igual. Quero modelo para fazer diferente."

Mesmo assim Donaldo evitou trair as intenções do autor (se é que se pode falar hoje em intenções do autor) e buscou preservar tanto quanto possível a essência dos diálogos e personagens.

No tocante ao conto infantil de Joyce, embora já existam duas traduções dele no mercado (a primeira tradução, de Lya Luft, aparece em nota de rodapé no livro James Joyce, de Richard Ellmann; a segunda tradução, de Antonio Houaiss, ganhou uma publicação em livro dedicado ao público infanto-juvenil), propus-me a oferecer a minha versão para o mesmo, mantendo o bilingüismo do texto original e lançando mão de notas explicativas. Ao fazer isso, depareime, nas poucas páginas da narrativa, com alguns dos problemas enfrentados pelos tradutores de sua obra para adultos, como, por exemplo, a mescla de línguas e as referências históricas. Para tentar solucionar esses impasses da tradução, optei por deixar no corpo do texto a língua francesa do diabo, já que a diversidade de línguas no conto é explicada no final pelo próprio Joyce. Mas já que o texto visa ao público infanto-juvenil, senti a necessidade de acrescentar uma nota com a tradução, para o português, da fala do diabo. De fato, a tradução de livros para crianças, como apontam alguns estudiosos, vem "freqüentemente acompanhada de explicações, de notas de substituição, de simplificações e encurtamentos" e de um certo apagamento das diferenças culturais em nome de uma certa moral. ${ }^{9}$

Poder-se-ia dizer, então, que "tanto a tradução quanto a adaptação envolvem reprodução e transposição. A adaptação seria, algumas vezes, como a tradução, restrita à reformulação [rewording], con-

9. AMORIM, Lauro Maia. Tradução e adaptação: encruzilhadas de textualidade em Alice no País das Maravilhas, de Lewis Carroll, e Kim, de Rudyard Kipling. São Paulo: UNESP, 2005, p. 102. 
siderada (...) como um processo de simplificação de um texto com o objetivo de torná-lo acessível a um determinado público. A adaptação poderia, também, efetuar uma atualização de textos de um passado remoto para leitores contemporâneos. Em ambos os casos, (...) estaríamos tratando de uma 'tradução interlingual', tal como classificada pelo lingüista Jakobson". ${ }^{10}$

Convém lembrar ainda que, como enfatiza M. A Johnson, mencionado por Lauro Amorim, no seu livro, Tradução e Adaptação: Encruzilhadas de Textualidade em Alice no País das Maravilhas, de Lewis Carroll, e Kim, de Rudyard Kipling, "embora traduções e adaptações raramente sejam transposições sem falhas em relação aos textos originais, um certo grau de fidelidade é requerido". Mas, na tradução, haveria fidelidade "tanto à forma quanto ao conteúdo, ao passo que, na adaptação, ocorreria fidelidade apenas ao conteúdo". Certos teóricos, como resumiu Amorim, opinam que "a adaptação seria assim mais flexível e daria espaço para modificações, acréscimos e subtrações ditados pelo formato-alvo, embora esse pressuposto possa não ser válido para certos casos". Certo é que "tanto a tradução quanto a adaptação requerem (...) disciplina e dedicação, podendo ter motivações semelhantes".${ }^{11}$ Sendo que, em última análise, "tanto a tradução quanto a adaptação são formas de 'apropriação' que possibilitam um determinado modo de aceitabilidade daquilo que é 'apropriado'". ${ }^{12}$

Diria que traduzir e adaptar, no contexto infanto-juvenil, são termos que caminham lada a lado, uma vez que transformam o texto naquilo que compreendemos, ou que podemos compreender. Desse modo, ficamos entre o gato e o diabo, sem saber para que lado nos lançar, como no conto de Joyce, em que os personagens têm de fazer uma escolha e estão paralisados, mas finalmente se encontra uma solução, recorrendo-se à esperteza e ao inesperado.

\footnotetext{
Idem, p. 78.

1 Idem, p. 78-79.

12 Idem, p. 106.
} 
Dirce Waltrick do Amarante. Joyce para crianças brasileiras

\section{Fragmento de "O Gato e o Diabo" na minha tradução}

Assim que o prefeito chegou na cabeceira da ponte, os homens seguraram a respiração e as mulheres seguraram suas línguas. $\mathrm{O}$ prefeito pôs o gato na ponte e, rápido como um raio, splash!, virou todo o balde de água em cima dele. $\mathrm{O}$ gato, que estava agora entre o diabo e um balde de água, mais que rapidamente decidiu atravessar a ponte a toda, as orelhas para trás, e se jogou nos braços do diabo.

O diabo ficou bravo como o diabo.

"Messieurs les Balgentiens", gritava do outro lado da ponte, "vous n'êtes pas de belles gens du tout! Vous n'êtes que des chats!13" E disse ao gato: "Viens ici, mon petit Chat! Tu as peur mon petit chou-chat? Tu as froid, mon petit chou-chat? Viens ici, le diable t'emporte! On va se chauffer tous les deux. ${ }^{4 \prime \prime}$

E sumiu com o gato.

E, depois disso, os moradores dessa cidade passaram a ser chamados de "les chats de Beaugency"15.

Mas a ponte ainda está lá e as crianças caminham por ela, andam de bicicleta e brincam nela.

Espero que você goste dessa história.

Nonno $^{16}$

P.S.: O diabo fala, na maior parte do tempo, uma língua própria, chamada diababelês, que ele inventa por aí, mas, quando fica muito furioso, pode expressar-se num francês muito ruim, contudo, aqueles que o escutaram, asseguram que ele tem forte sotaque de Dublin. (N. do A.)

13 “Senhores de Beaugency, vocês não são nem um pouco gentis! Vocês não passam de gatos!"

14 "Vem aqui, meu gatinho. Você está com medo, meu amorzinho? Está com frio, meu amorzinho? Vem aqui, o diabo te carrega! Vamos nos esquentar, nós dois juntinhos."

15 Os gatos de Beaugency.

16 Vovô, em italiano. 
When the lord mayor came to the head of the bridge every man held his breath and every woman held her tongue. The lord mayor put the cat down on the bridge and, quick as a thought, splash! he emptied the whole bucket of water over it. The cat who was now between the devil and the bucket of water made up his mind quite as quickly and ran with his ears back across the bridge and into the devil's arms.

The devil was as angry as the devil himself.

"Messieurs les Balgentiens", he shouted across the bridge, "vous n'êtes pas de belles gens du tout! Vous n'êtes que des chats!" And he said to the cat: "Viens ici, mon petit Chat! Tu as peur mon petit chou-chat? Tu as froid, mon petit chou-chat? Viens ici, le diable t'emporte! On va se chauffer tous les deux".

And off he went with the cat.

And since that time the people of that town are called "les chats de Beaugency".

But the bridge is still there and there are boys walking and riding and playing upon it.

I hope you will like this story.

Nonno

P.S. The devil mostly speaks a language of his own called Bellsybabble which he makes up himself as he goes along but when he is very angry he can speak quite bad French very well though some who have heard him say that he has a strong Dublin accent. 